\title{
RAÇA, CLASSE E ETNIA \\ NOS ESTUDOS SOBRE E EM CABO VERDE: \\ AS MARCAS DO SILÊNCIO
}

\section{Cláudio Alves Furtado*}

$\mathrm{U}$

ma análise dos estudos realizados por pesquisadores caboverdianos, nas últimas cinco décadas, mostra que, independentemente do quadro teórico no qual se inserem algumas categorias conceituais, erigidas como centrais, faz emergir ausências que denotam escolhas, por vezes ideologicamente situadas e que singularizam a produção teórica e ensaísta sobre Cabo Verde.

De forma específica, existe a percepção, a partir de uma leitura longitudinal e transversal, de que os estudos sobre Cabo Verde, produzidos essencialmente por pesquisadores locais, têm, em regra, sido omissos relativamente às dimensões da raça e da etnia na explicação da constituição e da transformação social da comunidade insular. Já as análises que têm como tema ou como centralidade as classes sociais aparecem com uma regularidade relativa, ainda que não possam ser consideradas estruturalmente marcantes.

Em contrapartida, os estudos produzidos desde meados dos anos oitenta do século passado, sobretudo nos Estados Unidos da América e incidindo sobre Cabo Verde, têm tido como categorias analíticas cen-

Professor da Universidade Federal da Bahia. 
trais precisamente as que se encontram ausentes nos estudos feitos por pesquisadores do arquipélago. ${ }^{1}$

O presente texto pretende fazer emergir, a partir de uma reflexão ainda em construção, eventuais pistas que possam ajudar a explicar o silêncio e/ou a relativa ausência de produções em Ciências Sociais que esbocem ou tenham como referencial explicativo os conceitos de classes sociais, raça e etnia. Cremos que as fronteiras e os mutantes marcadores identitários, por um lado, e a sublimação e/ou a negação de valências identitárias não hegemônicas, por outro, são cruciais para o entendimento desse silêncio, das omissões ou das transmutações conceptuais.

Com efeito, tanto no período colonial quanto no pós-colonial, raras são as tentativas de se compreender sociologicamente como, em Cabo Verde, os diversos atores emergem e se constroem enquanto sujeitos históricos. É muito mais comum encontrar-se uma preocupação em situar e definir a especificidade do homem, da cultura e da sociedade cabo-verdiana.

Tal situação, num primeiro momento, parece-nos decorrer menos da busca da construção de uma identidade nacional ou de sua fixação, e mais de uma necessidade de segurança ontológica ou psicossociológica.

Já num segundo momento, pode-se perceber, de forma mais ou menos orgânica e de cunho relativamente emancipador, uma preocupação com a construção, pela elite, de discursos identitários nacionalmente assumidos. ${ }^{2}$

Alguns deles, mais descritivos do que explicativos, fazem deter-

1 O presente texto constitui o resultado parcial de um projeto de pesquisa mais vasto e que procura analisar, de forma comparativa, as presenças e as ausências das categorias "classe", "raça" e "etnicidade" nos estudos em Ciências Sociais e Humanas sobre Cabo Verde. Uma primeira aproximação reflexiva foi apresentada e discutida na Conferência Lusofonia and Anthropology,organizada em abril de 2009 pelos Center for International Studies, Center for Latin American Studies, Center for the Study of Race, Politics and Culture, and the Department of Anthropology, da Universidade de Chicago.

2 Gabriel Fernandes faz uma análise extremamente fina dos diversos discursos e percursos identitários que marcam a trajetória do arquipélago crioulo durante o século $\mathrm{XX}$, e que se espraiam numa luta tenaz por imposição de um discurso identitário nacional legítimo. Voltaremos a esse autor mais à frente. Cf. Gabriel Fernandes, A diluição da África. Uma interpretação da saga identitária cabo-verdiana no panorama político (pós) colonial, Florianópolis: Editora da UFSC, 2002. 
minadas incursões pelas dimensões classe e raça, essencialmente na busca de modos de legitimação de uma sociedade que se forma a partir da extinção da sociedade escravocrata.

Não raras vezes, os conceitos ou as dimensões raça e classe se sobrepõem, sobretudo em contextos em que as condições sócio-históricas tenderam a favorecer uma homogeneização dessas duas categorias.

Em contrapartida, a dimensão étnica é referida no essencial, para justificar a impossibilidade de sua análise. Na verdade, a multiplicidade de etnias, que teriam concorrido para o povoamento das ilhas de Cabo Verde e a sua diluição no espaço do arquipélago, é erigida como fundamentos da emergência de uma sociedade, de um povo e de uma cultura particulares. ${ }^{3}$ Como sugere José Carlos dos Anjos,

A violência física e simbólica, que destruiu grande parte da memória étnica dos escravizados, tem sido lida pelos intelectuais cabo-verdianos como "fusão cultural de europeus e africanos". Essa "fusão cultural" numa mestiçagem geral é percebida por uma parte da intelectualidade cabo-verdiana como positiva, no sentido de que se teria constituído uma unidade nacional antes da implantação de um Estado nacional. ${ }^{4}$

Em alguns casos, emergiram críticas às raras abordagens de natureza culturalista, centradas na questão étnica. Amílcar Cabral, ${ }^{5}$ embora considere a luta de libertação com um ato de cultura, não deixa de criticar, assim como o faz Frantz Fanon, os que assentam a sua análise nas determinantes identitárias ou raciais e étnicas, esquecendo, em contrapartida, questões que se prendem às variáveis econômicas, sociais e

\footnotetext{
António Carreira, no seu estudo,Cabo Verde, formação e extinção de uma sociedade escravocrata (1460-1878), Praia: Instituto Nacional de Património Cultural, 2000, faz, a partir de uma vasta compilação documental, um inventário dos grupos étnicos que terão concorrido para o povoamento do arquipélago, citando, especificamente, os mandingas, os jalofos e os fulas. Contudo, confessa que a diversidade do elemento humano com que se fez o povoamento coloca um conjunto de implicações, sendo a maior a miscigenação. De igual modo, Elisa Andrade sustenta que a grande diversidade étnica torna a população cabo-verdiana extremamente heterogênea. Cf. Elisa Andrade, As ilhas de Cabo de Verde: da descoberta à independência nacional (1460-1975), Paris: L'Harmathan, 1996, p. 51.

4 José Carlos dos Anjos, "Elites intelectuais e a conformação da identidade nacional em Cabo Verde", Estudos Afro-Asiáticos, ano 25, n. 3 (2003), p. 581.

Amílcar Cabral, Unidade e luta, Lisboa: Nova Aurora, 1974.
} 
políticas. ${ }^{6}$ No que diz respeito à análise de classes socais e raças, encontramos uma tentativa de António Carreira de caracterizar a estrutura socioeconômica de Cabo Verde no período colonial e, de forma particular, no contexto da escravidão. ${ }^{7}$ Trata-se de uma démarche nitidamente funcionalista em que, de forma sinônima, classe e raça se sobrepõem. Com efeito, constata o autor que, durante os primeiros três séculos da colonização, "a sociedade cabo-verdiana estava estruturada em duas únicas classes: uma, a dos senhores (brancos, reinóis ou naturais e alguns mulatos), e outra, a dos libertos (negros ou mulatos) e escravos". ${ }^{8}$

Elisa Andrade virá, mais tarde, recaracterizar a sociedade caboverdiana em sua configuração social através do marxismo, recorrendo a N. Poulantzas. Para além da posição dos agentes no mundo da produção econômica, a autora agrega outras dimensões, incluindo os que permitem o agrupamento, numa mesma classe, de sujeitos inseridos em bases econômicas diversas, mas que partilham o mesmo quadro político e ideológico. No contexto colonial, a reconceituação de classes sociais permitiria, segundo a autora, captar especificidades de uma economia dependente, colonial e sem base industrial. ${ }^{9}$

Grande parte dos estudos realizados no contexto pós-colonial tende a concentrar-se na questão identitária e na construção da nação. Nesse contexto, a problemática da estruturação social e da pertença étnica ou racial inclina-se a estar omissa ou sublimada, para se privilegiarem as bases culturais diferenciadoras da nação e do homem cabo-verdiano, bem como de seu ethos específico. Esses estudos, como se poderá ver mais à frente, não são homogêneos. Comportam, antes, diferenças teóricas e políticas marcantes, com consequências societárias também diversas.

De certa forma, e a título de hipótese, poder-se-ia afirmar que a discussão em torno da identidade étnica é transmutada em identidade

Michael G. Hanchard assinala essa crítica de Cabral e Fanon às abordagens culturalistas. Cf. Michael Hanchard, Orfeu e o poder: movimento negro no Rio e São Paulo, Rio de Janeiro: Editora da UERJ, 2001.

7 António Carreira, Cabo Verde: formação e extinção; António Carreira, Cabo Verde (aspectos sociais: secas e fomes do século XX), Lisboa: Ulmeiro, 1984.

Carreira, Cabo Verde, formação e extinção, p. 288.

9 Elisa Andrade, As ilhas de Cabo Verde. 
cultural e/ou nacional, conhecendo oscilações históricas entre a africanidade, a crioulidade e a europeidade cabo-verdianas, para, numa postura por vezes intelectualmente cínica e vazia de capacidade heurística, se afirmar que a identidade dos insulares, não se resume numa coisa nem noutra: ela é simplesmente cabo-verdiana. ${ }^{10}$

A negação/sublimação/omissão da dimensão étnico-racial, tanto no discurso das ciências sociais, quanto na prática discursiva do quotidiano, encontra eco no silêncio das estatísticas demográficas que, já no período colonial, em meados dos anos quarenta do século passado, deixaram de diferenciar os agrupamentos populacionais segundo a raça, no sentido fenotípico do termo, prática continuada no período pós-colonial.

Contudo, a partir da análise das relações sociais, podem ser surpreendidos comportamentos estereotipados. Com efeito, parece-nos que, em muitos contextos, a etnicidade pode ser apreendida a partir de práticas que conduzem à criação de estereótipos negativos, alocados a grupos populacionais provenientes de espaços sociais nacionais bem específicos, ou seja, a etnicização, no contexto do espaço geográfico interno, é associada a outro contexto específico, que provém do continente. Existiria, aqui, uma reapropriação e uma ressignificação do conceito de etnia, que não se caracterizaria, como sugere A. D. Smith, como "existência de um nome próprio comum, de um mito de uma ancestralidade compartilhada, de memórias históricas compartilhadas, de elementos de uma cultura comum, de um vínculo a um homeland, e de senso comum de solidariedade", ${ }^{11}$ mas, antes, como um outro, homogeneizado numa designação étnica única (mandjakus), legitimada pela origem geográfica - continente - e por uma racialização disforme - negro. ${ }^{12}$

${ }^{10}$ Interessante observar que a oscilação tripolar se dá entre africanidade/cabo-verdianidade/ europeidade e não entre "branquidade/crioulidade-mestiçagem/"negritude". A questão da cor não parece ser analítica e discursivamente importante, podendo, antes, ser emocionalmente perturbadora para uma identidade que se quer sui generis.

11 Citado por Sergio Costa, As cores de Ercília: esfera pública, democracia, configurações pós-coloniais, Belo Horizonte: Editora da UFMG, 2002, pp.123-4.

12 Dizemos racialização disforme porque, embora a conotação primeira seja fenotípica, a heterodenominação de negro ao imigrante proveniente do continente pode ser estendida àqueles, também imigrantes, que são mestiços. 
Da mesma forma, e mais atualmente, as dinâmicas interculturais resultantes da imigração de africanos provenientes da África Ocidental fizeram emergir, no discurso e nas práticas sociais e culturais dos caboverdianos, comportamentos assentes na diferenciação étnica e racial, com recortes que, por vezes, indiciam certa esquizofrenia comunitária.

\section{Situando o problema}

Livio Sansone defende que etnia, etnicidade e demais derivados estão na moda. Com efeito, no mercado, essas categorias tornaram-se produtos comercializáveis, na política e na sociedade, termos "politicamente corretos" na academia foram erigidos como categorias explicativas importantes para se compreender a dinâmica das comunidades pluriétnicas e plurirraciais. ${ }^{13}$

Para o autor, as possibilidades de uma utilização contra-hegemônica dessas categorias explicativas, seja numa perspectiva epistemológica, seja política, seriam remotas. Afirma Sansone estar "mais cético do que nunca a respeito de qualquer possibilidade libertária e emancipatória intrínseca da mobilização política em torno da identidade étnica e da 'raça'". ${ }^{14}$ No contexto cabo-verdiano, essa possibilidade sequer se coloca, pela absoluta ausência dessas categorias de análise nos estudos e nas práticas discursivas quotidianas. Mesmo a questão do mercado étnico apenas se coloca de forma extrovertida. Aplica-se às comunidades emigradas no exterior, na perspectiva em que podem ser consideradas como importantes segmentos de um mercado étnico para produtos caboverdianos, passíveis de exportação.

De um ponto de vista estritamente conceitual, parece adequado ter em conta que etnicidade constitui "um constructo social de caráter contingente". Nesse sentido, não parece adequado e heuristicamente produtivo essencializá-la. No máximo colocar entre parênteses a etnicidade, retirando sua dimensão contingente, a sua historicidade, enfim.

Bader chama a atenção para o fato de o conceito de etnicidade

${ }^{13}$ Livio Sansone, Negritude sem etnicidade, Salvador/Rio de Janeiro: Edufba/Pallas, 2007.

${ }^{14}$ Sansone, Negritude, p. 10. 
reagrupar, hoje em dia, sentidos múltiplos, transformando-se no que denominou conceito contentor. ${ }^{15} \mathrm{Na}$ verdade, seriam vários os critérios que se imbricam para conformar o conceito:

[...] características comuns reais ou presumidas da cor da pele etc., território, origens comuns (míticas), características comuns da história, do idioma ou dialectos, da cultura (étnica ou política), do habitus e dos estilos de vida, da religião, bem como da cidadania - todos os grupos possíveis ou impossíveis, categorizáveis de modo racista, são designados como 'minorias étnicas' tal como os indígenas na Austrália, os bascos, os flamengos, os católicos na Irlanda do Norte, os judeus ou arménios na diáspora, os 'imigrantes' na Alemanha, os imigrantes étnicos na América do Norte, os 'estrangeiros' legais, assim como ilegais etc. ${ }^{16}$

De igual modo, tentando proceder à busca de interfaces de etnicidade e raça, Sansone chama a atenção para o perigo da naturalização desse último conceito, ainda que, como sugere Costa, na mesma esteira de Guimarães, ${ }^{17}$ se trate de um produto "de formas de classificações sociais com implicações substantivas para as oportunidades individuais no interior dos diferentes grupos socais". ${ }^{18}$ Assim, uma leitura atenta das formas como o conceito de raça tem sido usado mostraria uma certa intercambialidade com o de etnia. Desse modo, pode-se considerar que "os grupos sociais têm sido racializados, etnicizados e novamente racializados, num processo que sempre funciona através de uma combinação de forças dentro e fora de determinado grupo étnico". ${ }^{19}$ No entanto, ainda que, em muitos estudos, as categorias raça e etnia se encontrem mescladas, quando não sobrepostas, uma diferenciação se impõe. Se adstrito à categoria raça estão critérios socialmente definidos e passíveis de visualização exterior, à categoria etnia estão associados critérios sócio-históricos e/ou culturais. ${ }^{20}$

\footnotetext{
15 Veit-Michael Bader, Racismo, etnicidade, cidadania: reflexões sociológicas e filosóficas, Porto: Afrontamento, 2008.

16 Bader, Racismo, etnicidade, p. 85.

17 Antônio Sérgio Guimarães, Racismo e anti-racismo no Brasil, São Paulo: Editora 34, 1999

${ }_{18}$ Costa, As cores, p. 142.

19 Sansone, Etnicidade, p. 19.

20 Bader, Racismo, etnicidade.
} 
Essa perspectiva analítica mostra-se difícil de transportar para o caso cabo-verdiano. Na verdade, parece-nos que essas categorias analíticas não emergem como explicativas para a questão identitária, ou mesmo para se analisarem eventuais injunções entre a dimensão racial e as desigualdades sociais.

A não polarização analítica, em termos de identidade étnica e racial, é quase uma transversalidade em toda a história de Cabo Verde, e em todos os estudos sobre o país.

Nesse sentido, os estudos e as relações sociais em Cabo Verde tenderiam, numa certa dimensão, mutatis mutandis, a se aproximar da situação brasileira, referida por Sansone, segundo o qual as relações interétnicas e a racialização dos grupos se caracterizariam

(...) por um continuum racial ou de cor, em vez de um sistema não polarizado de classificação racial, por uma cordialidade transracial nas horas de lazer, entre as classes mais baixas, por uma longa história de sincretismo no campo da religião e da cultura popular, e por uma organização política relativamente fraca com base na 'raça' e na etnicidade, a despeito de uma longa história de discriminação racial. ${ }^{21}$

Essa aproximação é, contudo, apenas aparente, uma vez que, primeiro, a questão étnica é sublimada nas narrativas das ciências sociais e humanas, a partir do momento em que se assume que o fato colonial, pelos mecanismos sincréticos, refundou um povo e uma sociedade etnicamente homogêneos; segundo, a dimensão racial é, ela também, sublimada pela negação assertiva da africanidade (em termos culturais), vale dizer negritude, e uma negação tímida do europeísmo, levando a que se busque a superação na formulação vazia de significado e de capacidade heurística - "nem África nem Europa. Simplesmente Cabo Verde".

Embora o contexto cabo-verdiano comporte algumas especificidades, quando comparado aos estados africanos pós-coloniais continentais, as observações de Mkandawire sobre a presença e/ou a ausência de algumas categorias e dimensões na análise da realidade africana não relevantes, e podem, mutatis mutandis, ajudar a melhor refletir o caso cabo-verdiano. Sublinha esse autor que

${ }^{21}$ Sansone, Etnicidade, p.19. 
Em qualquer caso, tendo aceitado as fronteiras coloniais, eles tiveram que lidar com o fato concreto de que as nações constituíam de diversos grupos étnicos e nacionalidades. O pluralismo social da África, sua divisão em mais de mil grupos étnicos, sempre foi uma fonte de preocupação em termos de modernização, construção de nação, desenvolvimento e governança. Às vezes esse pluralismo tem sido central na análise, enquanto em outros momentos tem sido totalmente banido. Mas tem, como a espada de Dâmocles, pairado sobre qualquer outra categorização social utilizada na análise social: nação, classe ou gênero, sempre ameaçando tornar incoerente qualquer análise com base nessas categorias. ${ }^{22}$

Para as lideranças políticas dos estados pós-colonais, na era da euforia (primeira década das independências), o projeto de construção do Estado-Nação era, de certa forma, incompatível com os planos alternativos de nações-estados, multiculturalidade, multietnicidade ou dimensão multirracial. Aliás, pensar nesses termos e com essas categorias seria comprometer o projeto político de unidade nacional e de implementação do programa político de desenvolvimento.

Em Cabo Verde, ao contrário, pensar a realidade do país na sua eventual multiplicidade étnica, cultural e racial seria negar o fato de a nação preceder o Estado, negando a especificidade cabo-verdiana.

A situação cabo-verdiana apresenta nuances, contudo, importantes. Por um lado, a situação colonial muda o contexto e o padrão de relações sociais e de poder, com consequências na análise da estrutura social. Por outro, a tradição sincrética, no campo da religião, é muito mais fluida em Cabo Verde.

De igual modo, não se pode descurar que a vivência real ou imaginária e a reivindicação de uma identidade negro-africana, de africanismos ou da africanidade autêntica, num contexto de distanciamento geográfico de fronteiras opostas do Atlântico, se colocam de forma diferente, quando se está a $500 \mathrm{~km}$ do continente, onde a pertença geográfica não pode ser questionada.

${ }^{22}$ Tandika Mkandawire, African Intellectuals. Rethinking Politics, Language Gender and Development, Dakar: CODESRIA, 2005, p. 12. 
Parece evidente que a contestação da pertença geográfica de Cabo Verde ao continente africano é, de per si, impossível, podendo-se apenas argumentar no distanciamento identitário e cultural, mas não na dimensão étnica ou racial. Mais uma vez, a questão se colocaria, como muitos o fizeram, na crioulização e não na mestiçagem. ${ }^{23}$

Por sua vez, a dimensão racial raramente aparece como categoria de análise, contrariamente ao que sucede, por exemplo, entre os brasileiros, quando, nos anos 70,

o conceito raça, através, entre outros, da influência da discussão norteamericana, ganha renovada importância política no Brasil, funcionando como instrumento de ruptura da homogeneidade construída simbolicamente pela política de mestiçagem $[\ldots]^{24}$.

Mesmo no quadro do processo de reafricanização dos espíritos, propulsionado pelos intelectuais orgânicos da luta de libertação, a questão racial não é explicitamente colocada.

Nos estudos sobre Cabo Verde, as categorias analíticas centrais têm sido, majoritariamente, a mestiçagem e a crioulização, como elementos caracterizadores dos habitantes locais.

Para o caso da mestiçagem, trata-se, como o refere Sérgio Costa, de uma noção sociológica e não fenotípica, que fundamenta grande parte dos trabalhos dos construtores da cabo-verdianidade.

Já o conceito de crioulização é fortemente polissêmico, mudando de significado de acordo com autores e momentos históricos. No entanto, o que parece comum entre os autores, que o elegem como categoria explicativa, é a dimensão linguística, ou seja, a capacidade de produção de um novo instrumento de integração societário, e a criação de um ethos cultural específico não passível de ser subsumido nas suas matrizes.

23 José Carlos dos Anjos não compartilha dessa perspectiva. Para ele, "a definição dominante da identidade cabo-verdiana é a que, partindo do pressuposto de que houve uma fusão racial e cultural entre brancos e negros em Cabo Verde, torna-a mestiça". José Carlos Anjos, "Representações sobre a nação cabo-verdiana: definição mestiça da identidade nacional como ideologia do clientelismo em contexto de dominação racial". Fragmentos, n. 11/15 (1997), p. 13. Sustentamos que a dimensão racial apenas é utilizada na sua negatividade, isto é, para negála no seu sentido fenotípico.

${ }^{24}$ Costa, As cores, p. 249. 
Pode-se, nesse caso, apontar um paralelismo entre algumas construções identitárias e certas dimensões da cabo-verdianidade e a situação brasileira, aludida por Sérgio Costa, como o que caracterizaria os ideólogos da brasilidade de Freyre:

- A intervenção estatal no campo da cultura baseia-se num conceito essencialista de brasilidade, através do qual algumas formas culturais são promovidas, enquanto outras manifestações, igualmente existentes são sistematicamente desconsideradas;

- A brasilidade é apresentada como uma identidade mestiça não étnica, capaz de assimilar todas as outras representações étnicas.

A ideia de raça é desqualificada enquanto instrumento dos discursos públicos, ainda que continue orientando a acção e as hierarquizações estabelecidas pelos agentes sociais, cotidianamente. Assim, se constitui o mito da democracia racial, componente indispensável da ideologia da mestiçagem. ${ }^{25}$

Num primeiro momento, pode-se argumentar que a desvalorização da etnicidade, como categoria heuristicamente relevante para a compreensão da sociedade cabo-verdiana, reside na dificuldade de se identificar entre os "ilhéus" as etnias de origem ou de pertença. Nesse sentido, a pertença ou a afiliação étnica não passaria por uma ideia geral de uma ancestralidade africana, cultural e geograficamente situada, mas, antes, pela busca de novos referentes ou pela construção de outros.

Assim, a crioulização da sociedade cabo-verdiana emergiria como um processo de hibridação étnica, fator que torna mais complexa a análise, contrapondo-se à mestiçagem, que pode ser entendida como hibridização racial, no sentido fenotípico do termo.

Nos últimos anos, contudo, a negação ou a sublimação da dimensão étnica nos estudos sobre Cabo Verde, por um lado, e sua rejeição no plano social, por outro, são contemporâneas da construção de uma nova relação de alteridade que a imigração coloca. Com efeito, os afro-conti-

${ }^{25}$ Sérgio Costa, As cores, p.122. Nitidamente, a perspectiva dos claridosos poderia ser inscrita nesse quadro, ainda que Gilberto Freyre os tenha decepcionado. Cf. a esse propósito, Baltazar Lopes, Cabo Verde visto por Giberto Freyre, Praia: Imprensa Nacional, 1956; David Hopffer Almada, Cabo-verdianidade e lusotropicalismo, Recife: Fundação Joaquim Nabuco, 1999. 
nentais são reduzidos por um marcador étnico, mandjakos, ${ }^{26}$ que esconde um marcador racial, "negros".

\section{Análises histórico-sociológicas: da sobreposição de categorias às análises das classes sociais}

Como referido anteriormente, os estudos de natureza histórica, particularmente os considerados clássicos, conduzidos por Antonio Carreira, analisam a formação da sociedade cabo-verdiana, tentando determinar os aportes populacionais e culturais dos povos que concorreram para $\mathrm{o}$ seu povoamento.

Nitidamente, a situação colonial-escravista condiciona o povoamento e, por conseguinte, o peso relativo dos sujeitos intervenientes.

Analisando a formação social cabo-verdiana, num primeiro momento, a partir do conceito de classes sociais, Carreira tem uma postura crítica, relativamente aos estudos que concluem que "a sociedade insular teve por base indivíduos de duas classes: os europeus (fidalgos) e os escravos africanos". ${ }^{27}$

No entanto, e buscando uma análise comparativa, o autor tende a concordar com a análise para o contexto brasileiro, feita por Donald Pierson, para quem aventureiros, degredados, jovens ambiciosos, nobres empobrecidos, juízes e clero secular, judeus expulsos pela Inquisição, ciganos, prostitutas e órfãs e robustos camponeses teriam sido mandados para o povoamento da Bahia. ${ }^{28}$

Esses elementos permitiram a Carreira concluir que

as ilhas de Cabo Verde receberam, em maior ou menor número, elementos de todas as classes sociais registradas por Pierson. E, como pioneira da colonização lusíada, pôde fornecer ao Brasil alguns casais, brancos e mestiços, pardos e negros. ${ }^{29}$

${ }^{26}$ Mandjako é uma etnia da Guiné-Bissau e que concorreu com outras no povoamento de Cabo Verde, em cujo contexto, atualmente, "mandjako" foi transformado no gentílico para definir todos os imigrantes africanos continentais , independentemente de sua efetiva origem étnica e, por vezes, racial.

27 Carreira, Cabo Verde, formação, pp. 281-2.

28 Donald Pierson, Brancos e pretos na Bahia, São Paulo: Companhia Editora Nacional, 1945.

29 Carreira, Cabo Verde, formação, p. 283 
A concepção de classes por Carreira é sui generis, marcadamente funcionalista, tratando-se mais de grupos ou de categorias sociais.

Essa análise, que se assenta em classes, rapidamente se subsume em categoriais raciais. Com efeito, Carreira começa por descrever o peso relativo de brancos e negros na estrutura social e econômica das ilhas e os papéis sociais reservados a cada um desses atores. Da mesma forma, emerge já a problemática da mestiçagem, com o surgimento de pardos e mulatos. Diz ele: "Formava-se desse modo uma sociedade mista e escravocrata". ${ }^{30}$

Essa estrutura de classes, aproximando-se da situação da Bahia, descrita por Pierson, conhece, segundo Carreira, transformações no contexto das ilhas. Na verdade, nos finais do século XVIII, a estrutura social seria essencialmente dual, composta por senhores, de um lado, e libertos e escravos, do outro.

Nesse contexto, as dimensões classe e raça se cruzariam e se sobreporiam e, assim, diz o autor que "A sociedade cabo-verdiana estava estruturada em duas únicas classes: uma, a dos senhores (brancos, reinóis ou naturais, e alguns mulatos), e outra, a dos libertos (negros ou mulatos) e escravos". ${ }^{31}$ Pode-se aqui inferir que, embora a categoria raça venha a ser um importante recurso metodológico para a compreensão da conformação social cabo-verdiana e das eventuais desigualdades sociais, ela não constitui um fator único, até porque, mostra o autor, mulatos já faziam parte da classe dos senhores. De igual modo, estudos realizados, nomeadamente, no quadro da elaboração da história de Cabo Verde, evidenciam que, cedo, os "brancos da terra" passam a ser importantes proprietários, comerciantes e funcionários.

Nessa linha de ideias, como diria Jessé de Souza para o caso brasileiro, o preconceito seria de marca, ${ }^{32}$ tornando-se importante a di-

${ }^{30}$ Carreira, Cabo Verde, formação, p. 285.

31 Carreira, Cabo Verde, formação, p. 288.

32 "O preconceito, no Brasil, seria de marca precisamente porque a cor da pele ou os traços físicos são índices de primitividade, passíveis de serem "tornados invisíveis socialmente", desde que o indivíduo de cor seja portador do habitus adequado ao trabalho produtivo, nas condições do mercado competitivo moderno. Um negro ou um mulato instruído, disciplinado, inteligente e produtivo, nesse contexto, tende a receber uma avaliação social positiva do meio, independentemente de sua ascendência ou de seus traços físicos". Consultar a esse respeito, Jessé de Souza (org.), A invisibilidade da desigualdade brasileira, Belo Horizonte: Editora da UFMG, 2006, p. 89. 
mensão classe para o entendimento dos fundamentos da desigualdade social.

De igual modo, Sérgio Costa sublinha a necessidade de uma não utilização generalizada da categoria raça na análise sociológica, uma vez que o seu uso indiscriminado e construtivista tende a

tomar a realidade social como sendo um reflexo unilateral da estrutura socioeconômica, não levando em conta a forma como os agentes sociais descodificam as estruturas e constroem os significados que orientam seus comportamentos e escolhas. ${ }^{33}$

Assim, considera prudente e mais produtiva a utilização, em determinados contextos, da categoria segregação.

Voltando a António Carreira, num outro estudo, ele introduz novas categorias de análise (classes sociais), ainda que incorra na sobreposição classes/raças. No seu estudo sobre aspectos sociais, secas e fomes no século XX, ao analisar a organização da sociedade cabo-verdiana, afirma que, já a partir dos anos trinta do século passado, emergiu uma nova burguesia, proveniente da emigração, que viria substituir os "brancos da terra". De igual modo, faz referência a uma pequena burguesia urbana, comercial e administrativa e a uma "massa de trabalhadores rurais e outros".

Contudo, não resiste o autor a remeter para a questão racial o melhor entendimento dessas classes sociais, sem explicitar que tipos de correlações poderiam ser feitas, nem as inferências passíveis de serem produzidas, a partir do cruzamento das duas variáveis (classe e raça). Assim, diz expressamente que "No sentido de se poder compreender melhor a posição dessas camadas da sociedade insular, talvez não seja descabido dar a conhecer a composição da população segundo a cor, isto em relação aos poucos anos em que este atributo fez parte dos instrumentos de notação estatística: 1910-1919, 1920-1929 e 1930-1936". ${ }^{34}$

Elisa Andrade retoma a análise da estrutura social cabo-verdiana, fazendo um exame longitudinal que vai da descoberta à independên-

Costa, As cores, p. 145.

${ }^{34}$ Carreira, Cabo Verde, aspectos sociais, p.143. 
cia. ${ }^{35}$ Ancorando-se na tradição marxista, a autora analisa e concebe uma taxonomia que se aproxima da proposta por Carreira. Com efeito, para ela, a sociedade cabo-verdiana no final do período colonial estaria constituída por três classes: a burguesia local, dependente da "metropolitana", uma classe média, por ela denominada de "pequena burguesia", constituída pelos funcionários do Estado e do setor privado e, finalmente, "a grande massa" ou o "povo", incluindo os assalariados urbanos e os trabalhadores rurais.

Esse tipo de estudo, que oscila entre o funcionalismo e o marxismo, com muitas dificuldades de categorização e de base empírica, encontra-se presente em vários autores. Leila Hernandez e Michel Lessourd também incorrem na mesma linha de interpretação, ficando difícil a articulação entre a categoria sociológica "classes sociais" e a realidade empírica que pretensamente pretendem explicar. ${ }^{36}$

Em alguns momentos, tanto Carreira como Andrade, ensaiam quantificar o peso demográfico relativo de cada uma dessas classes sociais, sem nunca explicitarem os fundamentos sociológicos e estatísticos sobre os quais se assentaram os cálculos.

Maria Manuela Afonso afasta-se das análises mais comuns, que têm centralidade na categoria "classes sociais", tentando um exercício de reconceituação. Recusa "a orientação marxista tradicional", porque ignora a "origem política da mobilidade social", e acrescenta: "consideramos as classes como categorias de pessoas que partilham interesses econômicos e políticos comuns e que surgem do seu acesso aos poderes e aos recursos públicos e oportunidade de os controlar". ${ }^{37}$

Assim, para a autora, a definição de classes sociais, no contexto cabo-verdiano, deve ser construída a partir das relações de poder e não de produção. A aproximação de Pierre Bourdieu mostra-se evidente. É o quantum de poder possuído e o posicionamento no campo político

35 Andrade, As ilhas de Cabo Verde, pp. 235 e ss.

${ }^{36}$ Leila Hernandez, Os filhos da terra do sol: a formação do estado-nação em Cabo Verde, São Paulo: Summus, 2002; Michel Lessourd, Etat et société aux îles du Cap Vert, Paris: Karthala, 1995.

37 Maria Manuela Afonso, Educação e classes sociais em Cabo Verde, Praia: Spleen Edições, 2002, p. 25. 
que definem a posição de classe e que, por sua vez, permitem o acesso aos recursos econômicos. Existe, portanto, uma anterioridade do político em relação ao econômico, sendo o primeiro a fonte da "acumulação primitiva", para utilizar uma expressão marxista.

O acesso ao poder e, por via desse, ao econômico, passa pela educação, importante via de mobilidade, tanto no período colonial quanto no pós-colonial. A possibilidade de acesso à administração pública colonial passa pela escolarização e é, também, por ela (posse de títulos escolares) que, progressiva e solidamente, se tem acesso ao poder e aos recursos públicos no estado pós-colonial.

No entanto, quando a autora procura fazer uma reconstrução histórica do processo de estruturação social em Cabo Verde, deixa de lado a proposição teórica inicialmente feita para abraçar as abordagens já tradicionais na historiografia local. O conceito de classes transmuta-se no de raça. Reconhece M. Afonso que "fazer uma análise evolutiva da estrutura de classes, partindo dos resultados dos censos, mostrou-se impraticável". ${ }^{38}$ Afirma, porém, que, "nos primeiros séculos de ocupação a diferenciação social existente era sobretudo racial", ${ }^{39}$ corroborando a conclusão de Correia e Silva, para quem, em sociedades crioulas, "as fracturas étnicas inicialmente coincidiam com as de classe, fazendo do negro, escravo, e do branco, escravocrata, daquele o 'gentio' e deste o civilizado". Reconhecendo, embora, que "não é menos certo que a própria dinâmica histórica dessas mesmas sociedades, ou seja, a luta entre as classes que as compõem, faz baralhar estes dados (dinâmica de crioulização)" ${ }^{40}$

Como se pode ver, a perspectiva analítica da formação social caboverdiana, que tenha centralidade na categoria "classes sociais", para além de ser pouco significativa e pouco substantiva, tende a perder a sua capacidade explicativa, seja pela existência de uma dissonância entre as dimensões teórica e empírica, seja porque, amiúde, se vê subsumida na categoria raça.

38 Afonso, Educação e classes, p. 82.

39 Afonso, Educação e classes, p. 83

40 António Leão Correia e Silva, Histórias de um sahel insular, Praia: Spleen Edições, 1996. 


\section{Entre a mestiçagem e a crioulização: o étnico-racial e a especificidade cultural}

Uma parte substancial dos estudos sobre Cabo Verde erige como categorias analíticas centrais a mestiçagem e a crioulidade.

Nessa perspectiva, a melhor forma de se compreender a formação social cabo-verdiana passa pelo entendimento do processo que terá, para uns, conduzido a uma hegemonia de uma população e uma cultura mestiças e, para outros, à emergência de uma comunidade crioula.

A noção de mestiçagem aparece, em geral, oscilando entre a dimensão fenotípica e a categorização sociológica, ou ainda recobrindo as duas dimensões.

Gabriel Mariano é, sem dúvida, o grande explicitador da defesa de um Cabo Verde como sendo o mundo que o mulato criou. Sublinha esse autor que, em Cabo Verde, terão desabrochado expressões novas de cultura, essencialmente mestiças.

Desde as suas origens mais remotas que no arquipélago puderam o negro e o mulato apropriar-se de elementos da civilização europeia e senti-los como seus próprios, interiorizando-os e despojando-os das suas particularidades contingentes ou meramente especificas do europeu. Com efeito, os elementos introduzidos com os portugueses, tanto materiais como espirituais, puderam ser incorporados na paisagem moral do arquipélago, passando a ressoar com familiaridade, quer no comportamento do negro, que no mulato, influindo, por conseguinte, nas suas reações mais íntimas. Da mesma forma que elementos levados pelos afro-negros foram assimilados pelo branco europeu, tornando-se irremediavelmente comuns aos dois grupos étnicos. ${ }^{41}$

António Carreira perfilha a posição de Gabriel Mariano, ao afirmar a hegemonia de uma população e de uma cultura mestiças no contexto cabo-verdiano. A fundamentação da tese repousa essencialmente na dimensão demográfica. Com efeito, para Carreira, a reduzida presença de mulheres brancas conduz a que os brancos reinóis rapidamen-

${ }^{41}$ Gabriel Mariano, Cultura cabo-verdena: ensaios, Lisboa: Veja, 1991. 
te se casem ou se amiguem com as negras, levando a miscigenação aliada à diminuição da entrada de novos homens negros.

Essa é também a conclusão do estudo seroantropológico realizado em Cabo Verde, sob a orientação de Almerindo Lessa e Jacques Ruffié, ${ }^{42}$ para os quais o mestiço terá acabado "por dominar o espaço físico e intelectual do Arquipélago", tornando-o "um dos mais extraordinários fenômenos humanos de que reza a história nacional”, vale dizer, portuguesa.

Contrapondo-se à mestiçagem, encontramos um conjunto de estudos que analisa a sociedade cabo-verdiana na sua dimensão crioula. Alguns não vêm a crioulidade como uma especificidade insular, mas antes como um traço de formações sociais que se constituem em espaços ilhéus, resultantes de um povoamento interétnico e intercultural.

Nesse caso, a formação social cabo-verdiana se inscreveria no mesmo quadro classificatório que S. Tomé e Príncipe e das Antilhas.

Essa é a perspectiva de Antonio Correia e Silva, para quem "a crioulidade, [...] que é simultaneamente cultural, social e histórica, deriva da criação de uma sociedade a partir da integração de europeus e africanos sobre a hegemonia política dos primeiros". ${ }^{43}$ Trata-se, por conseguinte, de uma sociedade que emerge de um processo de hibridização étnico, social, político e cultural, caldeado pela dimensão geográfica. Por isso, cada sociedade crioula tem a sua especificidade que resulta "de lutas, tensões, acontecimentos que nela tiveram e têm lugar". ${ }^{44}$

De forma diversa entende Brito-Semedo a crioulidade. ${ }^{45}$ Ela é vista como uma especificidade identitária, mas também social e espacial. Nesse sentido, a categoria crioula, tal como ela é apropriada, não pode ser transposta, enquanto conceito, na busca de explicação para outras sociedades que, eventualmente, tenham tido percursos sócio-históricos semelhantes. Mais ainda, encontra-se subjacente a essa catego-

42 Almerindo Lessa \& Jacque Ruffié, Seroantropologia das ilhas de Cabo Verde, Lisboa: Junta de Investigações do Ultramar, 1960.

43 Correia e Silva, Histórias de um sahel, p. 59.

${ }^{44}$ Correia e Silva, Histórias de um sahel, p. 60.

45 Manuel Brito-Semedo, A construção da identidade nacional: análise da imprensa entre 1877 e 1975, Praia: Instituto da Biblioteca Nacional e do Livro, 2006. 
ria uma dimensão de subjetividade humana que conduziria à autonomização identitária. Afirma o autor que

[...] todo esse ambiente terá proporcionado ao mestiço nascido desse cruzamento, ainda sem uma identidade étnica definida, o confronto entre as diferenças culturais dos seus progenitores - a europeia do pai e a africana da mãe - e criar uma identidade cultural própria, a cultura crioula, que se caracterizava, essencialmente, por um sentimento de diferença. ${ }^{46}$

A apropriação dessa concepção de crioulidade e, mais ainda, de etnia, de uma forma problemática, leva o autor a, numa perspectiva nitidamente ideológica, valorizar, de forma oposta, as dimensões europeia e africana que concorreram para o processo de miscigenação. Com efeito, diz ele que

Ao lado de costumes e hábitos de importação europeia, encontram-se reminiscências de formas sociais, costumes e processos negro-africanos; amalgamando-se com pratos de cozinha puramente portuguesa, existem formas de alimentação de origem ou influência negro-africana; ao lado da família legitimamente constituída, detecta-se uma acentuada tendência poligâmica; a par da canção portuguesa ou ocidental, ondulam pelo ar a morna, o batuque, a finaçom. ${ }^{47}$

Como se pode ver, à positividade dos aportes europeus contrapõese a negatividade dos valores africanos; à não adjetivação fenotípica da contribuição europeia opõe-se a dimensão negra à contribuição africana; à hegemonia dos hábitos europeus têm-se as reminiscências africanas; ao casamento monogâmico europeu tem-se a poligamia africana.

Dessa análise por oposição, o autor chega, por negação, e de certa forma paradoxal, à sociedade crioula que, resultando embora do caldeamento das duas contribuições, não se resume a nenhuma delas e nem tampouco constitui a sua síntese. Seria, afirma o autor, com uma certa mistificação, " um caso sui generis".

${ }^{46}$ Brito-Semedo, A construção da identidade, p. 69.

47 Brito-Semedo, A construção da identidade, p. 70. 
Manuel Ferreira foi dos primeiros autores a, de forma mais sustentada teórica e empiricamente, defender a existência de uma sociedade cabo-verdiana crioula. Com efeito, faz recurso a uma vasta literatura em ciências sociais, que estudam as sociedades que experimentaram relações interétnicas, especialmente o Brasil, as Antilhas etc., para buscar corroborar a especificidade crioula de Cabo Verde que, para ele, seria desconhecida, porque não suficientemente estudada. As poucas análises feitas acabaram por se revelar enviesadas, no sentido em que contrariam as proposições do autor. ${ }^{48}$ No seu livro Aventura Crioula, o autor afirma que "[...] o problema da cor, o da origem racial, deixou literalmente de ter significação no Arquipélago [...]". ${ }^{49}$ Com efeito, ressalta, constata-se uma transmutação da dimensão raça para a social. Nesse sentido, a referência à cor tem um significado sociológico e não fenotípico.

Ali a própria designação 'gente branca' e aspectos derivativos: "casa de gente branco", 'cheiro de gente branca' se esvaziaram do seu conteúdo étnico para, semanticamente, incorporarem um significado em íntima conexão com as alterações sofridas nas estruturas econômicas do Arquipélago que, desde cedo, permitiram uma permeabilização social alheia à cor do indivíduo. ${ }^{50}$

Contestando autores precedentes, que teriam sublinhado a forte presença de elementos africanos no contexto social cabo-verdiano, como Auguste Chevalier e Gilberto Freyre, Ferreira sublinha o caráter ideológico das proposições desses autores. Em contrapartida, ressalta a singularidade cabo-verdiana, resultante da emergência de uma cultura nova, fruto do cruzamento de contribuições negras e europeias.

Esse essencialismo crioulo, refere o autor, pode ser constatado "[...] através da música, da poesia, da dança, da culinária, do crioulo, da literatura oral e do pessoalismo que as gentes imprimem a mil e uma manifestações da vida quotidiana [...]". ${ }^{51}$

48 Não queremos, contudo, afirmar que os posicionamentos desses autores fossem teórica e empiricamente sólidos.

49 Manuel Ferreira, A aventura crioula, Lisboa: Plátano Editora, 1985, p. 45.

${ }^{50}$ Ferreira, A aventura, p. 325.

51 Ferreira, A aventura, p. 326. 


\section{Africanidade, europeidade e cabo-verdianidade: dilemas identitários}

De forma sistemática, a reivindicação da dimensão africana na formação social cabo-verdiana aparece com os intelectuais orgânicos da luta de libertação nacional. Tanto sob a forma de crítica aos intelectuais defensores do regionalismo crioulo, como numa perspectiva que se classifica de emancipatória no quadro das lutas anticoloniais, percebe-se nitidamente a busca do resgate dos valores culturais do arquipélago. Manuel Duarte refere explicitamente que

Nós, os cabo-verdianos, estamos étnica e historicamente ligados tanto à África como à Europa, acrescendo sobremaneira no sentido da africanidade, a situação geográfica, o condicionamento climatérico, a predominância da corrente imigratória negra no povoamento das ilhas, originariamente desertas, em suma, o fenómeno colonial e suas necessárias implicações. ${ }^{52}$

Essa assunção da africanidade, num contexto sociopolítico importante, configura, como ressalta Gabriel Fernandes, uma reafricanização dos espíritos e o retorno às origens, ainda com alguma ambiguidade que, no entanto, atinge maior radicalidade com Amílcar Cabral. Esse posicionamento de Manuel Duarte ressalta, pela positividade, a dimensão africana da cultura cabo-verdiana.

José Luis Hopffer Almada caracteriza a população do arquipélago, do ponto de vista racial, como essencialmente mestiça. Sem apresentar dados demográficos e/ou fontes históricas que atestem a afirmação, sustenta que "Do ponto de vista 'racial', a comunidade se subdivide em mestiços (a maioria, com predominância mulata), pretos e brancos (estes, com uma relativamente fraca expressão numérica, quer histórica quer presentemente)". ${ }^{53}$ No entanto, acrescenta que "[...] em Santiago, os mestiços e os brancos são minoritários em relação aos pretos, ainda que, do ponto de vista absoluto, a grande ilha seja aquela que alberga o maior número de mestiços e brancos". ${ }^{54}$ Alguns problemas, como referido ante-

\footnotetext{
52 Manuel Duarte, Cabo-verdianidade e africanidade, Praia: Spleen, 1999, p. 27.

53 José Luís Hopffer Almada, "Homogeneidade e heterogeneidade da cabo-verdianidade", Fragmentos, n. 11/15 (2007), p. 28.

54 Hopffer Almada, "Homogeneidade e heterogeneidade", p. 28.
} 
riormente, se colocam, em primeiro, as estatísticas demográficas deixaram, ainda no período colonial, de classificar a população segundo a raça. ${ }^{55}$ Em segundo lugar, a taxonomia proposta não se encontra fundamentada, assim a diferenciação dos mestiços em subgrupos, nomeadamente os mulatos, não é alicerçada nem do ponto de vista da categoria, nem de sua base empírica.

Da mesma forma, sublinha que a miscigenação cultural é transversal a populações somaticamente diversas e a ilhas com distribuição populacional, em termos raciais também diferenciados.

Tal situação, na perspectiva desse autor, resulta do fato de se tratar de uma cultura crioula que emerge num

[...] arquipélago africano, macaronésico saheliano e atlântico, integra, por outro lado, o Novo Mundo, pois que o seu processo histórico resultou do surgimento das diásporas negro-africanas e europeias, sendo o seu corolário a nossa crioulidade. [Para arrematar que] o cabo-verdiano é, em todas as ilhas, portador de uma idêntica cultura crioula, miscigenada na sua substância e formas de expressão. ${ }^{56}$

Partilhando a mesma linha analítica, encontramos também David Hopffer Almada, para quem não se devem negar as contribuições negro-africanas e europeias na conformação sociocultural cabo-verdiana. Assim, sugere que

[...] a identidade nacional e cultural cabo-verdiana se assenta menos em cada um dos elementos referidos (hibridização, insularidade e ruralismo tropical) e mais na frontalidade das relações culturais étnicas, permitindo o surgimento de uma cultura não nova mas resultante dos vetores vários que confluíram ao arquipélago, preservando-se não como sobrevivências mas como reelaborações de traços culturais originários de grupos étnicos que outrora aportaram às ilhas. ${ }^{57}$

Observa-se que, de forma sistemática, a análise e a caracterização da formação social cabo-verdiana colocam grande parte dos auto-

55 Carreira, Cabo Verde, formação.

56 Hopffer-Almada, "Homogeneidade e heterogeneidade", p. 29.

57 D. Hopffer-Almada, Pela cultura e pela identidade. Em defesa da cabo-verdianidade, Praia: ICNL, 2006. p. 73. 
res, antes analisados, em armadilhas teóricas e identitárias importantes. Com efeito, a busca da singularidade de Cabo Verde, tanto do ponto de vista étnico como do cultural, leva a uma aceitação/rejeição do alinhamento a espaços étnicos e culturais outros. A aceitação dos aportes europeus, africanos ou atlânticos na estruturação das ilhas, perpassa todas essas análises, ao mesmo tempo em que demonstra que esses contributos deixaram de ser o que eram, para deles emergir uma formação social nova. Daí a rejeição.

A sociedade crioula, mestiça e atlântica seria, nessas análises, transétnica e transracial. Por isso, as categorias raça e etnia aparecem, apenas, marginalmente sem qualquer pretensão explicativa.

\section{Reposicionamentos analíticos}

Tem-se assistido, ainda que minoritariamente, a um esforço teórico extremamente sólido de um reposicionamento analítico sobre a estruturação da sociedade cabo-verdiana, desconstruindo perspectivas analíticas até então hegemônicas.

Um dos primeiros contributos nesse domínio vem de José Carlos dos Anjos que, analisando os discursos e as construções identitárias cabo-verdianas, os coloca num novo quadro epistemológico.

A identidade nacional é vista como uma construção político-discursiva e objeto de disputa nos diferentes campos que estruturam a formação social cabo-verdiana.

Um segundo aspecto importante tem a ver com o fato de este autor fazer emergir, da análise dos diversos discursos sobre a identidade, dimensões étnicas e raciais sublimadas, negadas, rejeitadas ou não assumidas.

Com efeito, a mestiçagem cultural reivindicada é colocada, pelo autor, na "sua posição numa estrutura de dominação racial". ${ }^{58}$ Contesta o que não tem sido questionado, isto é "[...] em que correlações de força (numa situação de dominação racial) surgiu o conceito de crioulo (en-

${ }^{58}$ Anjos, "Representações sobre a nação", p. 14. 
quanto mistura), a que interesses servia a percepção da realidade social permeada por tal categoria". 59

A centralidade analítica é posta, por um lado, nas relações sociais, econômicas, políticas e de poder entre grupos diversos e, por outro, na forma como a categoria étnico-racial mestiça resulta de um "produto de correlações sociais de força". Mais ainda, essa nova abordagem, salientando a hegemonia da identidade mestiça no campo da luta por imposição de princípios identitários, a transmutação de um conceito e de uma pertença grupal (mestiço) para um todo (nação), apagando as diferenças sociais e étnico-raciais e essencializando eventuais comunidades.

Gabriel Fernandes vem, de uma forma ainda mais profunda, modificar todo o quadro teórico e analítico dos estudos sobre Cabo Verde, no que diz respeito à interpretação sobre a constituição e a representação da nação. Trata-se, sem dúvida alguma, de um trabalho que induz a uma renovação epistemológica nos estudos sobre Cabo Verde. ${ }^{60}$

Erigindo, como outros o fizeram, a crioulidade/crioulização como categoria analítica de grande centralidade, Fernandes considera-a como política e heuristicamente importante para a compreensão da saga identitária cabo-verdiana e como veículo emancipatório.

Mais do que analisar a formação da sociedade mestiça, a perspectiva analítica introduzida conduz à compreensão da "crioulização em ação", da dimensão cosmopolita do discurso de crioulização, das estruturas de ação e dos processos de negociação entre os vários atores protagonistas.

Assim, propõe como recurso metodológico, por um lado, trabalhar nos interstícios das relações entre os discursos nacionais e as práticas coloniais e, por outro, os condicionamentos estruturais da sociedade cabo-verdiana, que terão influenciado os seus caminhos.

Operacionalizando essa démarche metodológica, a análise centrase nas seguintes dimensões: i) a forma como a crioulização terá dificultado a percepção da alteridade e, dessa maneira, a fragiliza enquanto

59 Anjos, "Representações sobre a nação", p.17.

${ }^{60}$ Gabriel António M. Fernandes, Em busca da nação: notas para uma reinterpretação do Cabo Verde crioulo, Florianópolis/Praia: Editora da UFSC/IBNL, 2006. 
marco identitário e recurso mobilizador; ii) a educação como facilitadora da autoconsciência crioula; a "diasporização" que ultrapassa a dimensão territorial da nação; e iii) os constructos político-ideológicos que terão dificultado a subjetivação nacionalista crioula e potencializado a sua marcha transnacionalista.

Nesse autor, a "crioulidade" ganha uma nova conceituação, permitindo, diferentemente de outras abordagens, surpreender novas determinantes da estruturação social e identitária de Cabo Verde, num quadro translocal.

Mais recentemente, novas análises têm surgido, procurando compreender e surpreender os discursos e as práticas classificatórias heteroimpostas, resultado das dinâmicas relacionais e de confronto, colocado pela presença de uma forte e crescente comunidade imigrada, proveniente dos países da CEDEAO (Comunidade Econômica dos Estados da África Ocidental).

Com efeito, parece que as dinâmicas interculturais, resultantes da presença de africanos provenientes da África Ocidental, fizeram emergir, no discurso e nas práticas sociais e culturais dos cabo-verdianos, comportamentos assentes na diferenciação étnica e racial, com recortes que, por vezes, indiciam certa esquizofrenia social.

Eufémia Rocha, num estudo recente, sublinha a existência de uma "identidade mandjaka imposta pelos cabo-verdianos em relação a esses imigrantes (provenientes dos países da costa ocidental africana) que não é, para muitos deles, uma identidade assumida". ${ }^{61}$

Essa identidade imposta resultaria, segundo a autora, de uma suposta superioridade dos cabo-verdianos, e que decorria de sua condição mestiça. Nesse caso, a dimensão raça emerge como categoria importante, uma vez que permite captar a percepção da diferenciação e da imposição de marcas de estigma no heteroclassificado.

Aqui, os marcadores identitários se apropriam da categoria, manipulando a dimensão étnica e negando a própria condição racial (feno-

${ }^{61}$ Eufémia Rocha, "Mandjakus são todos os africanos, todas as gentes que vêm da África: xenofobia e racismo em Cabo Verde" (Dissertação de Mestrado, Universidade de Cabo Verde, 2009), p. 13. 
típica) do sujeito produtor da classificação. Com efeito, a designação mandjako, porque de uma etnia se trata, tem como base de apropriação a raça (negro-africana), negando a condição negra do cabo-verdiano, uma vez que esse se assume como mestiço. Citando a autora antes referida que, por sua vez, transcreve a fala de um dos imigrantes, o caboverdiano considera e classifica: "mandjakus são todos os africanos, todas as gentes pretas que vêm da África". ${ }^{6}$

\section{À guisa de conclusão}

Em termos conclusivos, pode-se depreender da análise dos estudos de ciências sociais sobre Cabo Verde, sejam eles produzidos por pesquisadores locais, sejam por estudiosos estrangeiros, que tendem, na sua grande maioria, a não centrar a análise da estrutura e da formação social cabo-verdianas em torno de categorias socioantropológicas clássicas, como o são as de classe, etnia e raça.

Em regra geral, quando utilizadas, etnicidade e raça são, amiúde, transmutadas de uma categoria de conformação identitária, tendo a dimensão racial como elemento caracterizador exterior importante, para a da mestiçagem ou a da crioulidade.

Com efeito, a mestiçagem, quando aparece nesses estudos, é utilizada na sua dimensão cultural e identitária e não fenotípica. Trata-se, parece-nos, de um recurso analítico, mas também político e sociopsicológico, para situar e estruturar a formação social que, se quer sui generis, não pode ser reduzida a nenhuma das partes que concorreram para sua constituição, salvo quando a positividade existencial e ideológica justifica a aproximação de uma das partes com a consequente subalternização da outra.

Essas oscilações perpassam os diversos períodos históricos analisados, tendo também formulações diversas consoante os autores.

Resulta também da leitura dos estudos analisados em que, na maior parte dos casos, a centralidade das dimensões étnica e racial aparece essencialmente como categoria de análise do processo da formação, e

${ }^{62}$ Rocha “Manddjakus”, 73. 
não como categorias analíticas da estruturação da formação social caboverdiana.

É verdade, contudo, que, mais recentemente, tem-se assistido a uma inflexão paradigmática nos estudos sobre a construção da nação, fugindo da perspectiva, até então hegemônica, que a idealizava e a identidade cultural como essencialistas, orgânicas e homogeneizadoras. Essas abordagens não veem a nação como uma comunidade imaginada, uma construção e uma resultante de lutas por imposição de visões da sociedade cabo-verdiana.

Oscilando entre a predominância europeia e a africana, na conformação identitária, ou na emergência de uma cultura, de um povo e de uma nação sui generis e ex-novo, essas análises, que ainda continuam hegemônicas, comportam ou estão fortemente imbricadas em posicionamentos políticos e ideológicos bem concretos, que perpassam a história colonial e pós-colonial.

Contudo, começam a emergir, como referido anteriormente, análises que buscam situar a questão da nação e da identidade num novo marco teórico, tomando como referencial analítico, ora a categoria de mestiçagem, ora a de "crioulidade". ${ }^{63}$

Para o primeiro tipo de abordagem, a crioulização, central no discurso de construção identitária e presente nos das elites letradas caboverdianas, revela ser uma categoria eminentemente ideológica, que busca anular os antagonismos raciais que a presença de negros e brancos comporta, pretendendo apagar a própria dimensão fenotípica da categoria mestiço/mestiçagem.

Para o segundo, a crioulização, no contexto cabo-verdiano, emerge como uma categoria heuristicamente importante e politicamente emancipatória, ainda que, nessa última acepção, comporte importantes limites à mobilização e enquanto marco identitário.

A reconfrontação entre cabo-verdianos e africanos continentais, na última década, em decorrência dos fluxos migratórios dos países da

63 José Carlos dos Anjos, Intelectuais, literatura e poder em Cabo Verde: lutas de definição da identidade nacional, Porto Alegre/Praia: Editora da UFRGS \& INIPC, 2002; Fernandes, Em busca da nação. 
costa ocidental para o arquipélago, recoloca em análise a questão étnica e racial, já agora num novo patamar.

As categorias etnia e raça sobrepõem-se e tornam-se sinônimos, com o fito de homogeneizar os "outros", reforçando o "eu". Como refere Rocha, a categoria étnica "mandjaku” é transformada num marcador identitário racial, tornando todos os negros africanos continentais numa uniformidade étnica, não obstante a multiplicidade de pertenças étnicas e, portanto, identitárias dos imigrantes. ${ }^{64}$

Já as análises da formação social cabo-verdiana, que erigem a categoria de classes sociais como centralidade explicativa, utilizam esse conceito de uma forma que oscila de um funcionalismo e um instrumentalismo conceptual a uma abordagem marxista, aplicada a países periféricos e dependentes, primeiro num contexto colonial e, mais tarde, num de economias subdesenvolvidas periféricas. ${ }^{65}$

Em ambos os casos, percebe-se uma grande dificuldade de operacionalização do contexto e de sua aplicação à realidade empírica analisada, que resulta da própria dissonância entre o quadro teórico no qual se inserem a categoria analítica e a realidade, ela mesma.

Com efeito, a limitação explicativa, proposta por A. Carreira, reside na sobreposição por ele feita entre raça e classe ou estamento, sem uma explicitação conceptual e sem uma base sociodemográfica de suporte. Já para Elisa Andrade, os limites da abordagem proposta encontramse na pouca flexibilidade teórica e na dificuldade de sua transposição para uma sociedade não industrial, colonial e periférica.

São esses limites aos modelos teóricos clássicos, centrados no conceito de classes sociais, que levaram M. Afonso a introduzir uma inflexão no conceito, atribuindo à dimensão política um papel importante na conformação dessa categoria ${ }^{66} \mathrm{Se}$, na modelização teórica, a autora consegue, de fato, fazer um importante exercício de reconceitualização, que poderia permitir melhor entendimento da estrutura social cabo-verdiana, quando procura utilizar tal conceito para uma análise

\footnotetext{
${ }^{64}$ Rocha, "Mandjakus".

${ }_{65}$ Carreira, Cabo Verde, formação; Andrade, As ilhas de Cabo Verde.

66 Afonso, Educação e classes.
} 
diacrônica da sua formação, acaba por cair nas armadilhas das abordagens clássicas, o que limitou a qualidade do trabalho desenvolvido.

Independentemente das limitações encontradas nos estudos e nas análises sobre a formação social cabo-verdiana, constata-se um processo promissor emergente de novas perspectivas analíticas, seja em termos de sua capacidade explicativa, seja emancipatória. São, na sua essência, abordagens que emergem internamente e que, numa relação dialética interessante entre a dimensão empírica e o processo de construção de interessantes modelos de análise, buscam propor novos caminhos para o entendimento dessa realidade mutante e, como sublinha Fernandes, translocal e cosmopolita.

\title{
Texto recebido em 29/04/2011 e aprovado em 8/9/2011
}

\begin{abstract}
Resumo
O presente texto busca problematizar e compreender a forma como o contexto social influencia o processo de produção de conhecimento e como, implícita ou explicitamente, também influencia as escolhas temáticas e teóricoconceptuais, conduzindo a simulações e dissimulações, presenças e ausências. Centrando no caso cabo-verdiano e, especificamente, nos estudos de ciências sociais e humanas sobre Cabo Verde e, majoritariamente produzidos por caboverdianos, mostra-se existir, de forma quase unânime, uma ausência de categorias analíticas relevantes, tais como "classes sociais ", raça" e "etnia/etnicidade", para o estudo explicação da formação social cabo-verdiana. Em contrapartida, categorias, como " identidade", "cultura", "nação", "cabo-verdianidade" tendem a ser regidas como conceitos explicativos de referência.
\end{abstract}

Palavras-chave: Cabo Verde - classes sociais - raça - etnicidade

\begin{abstract}
This paper seeks to understand the influence of social context in the process of knowledge production and how, implicitly or explicitly, it also shapes the choice of themes, theories and concepts, leading to simulations and dissimulations, presences and absences. Taking Cape Verde as a case study, specifically studies of this archipelago conducted in the social sciences and humanities, in the most part by Capeverdean researchers, the present paper reveals an almost complete lack of relevant analytical categories such as "social class" "race" and "ethnic/ethnicity" in explaining the social formation of Cape Verde. In contrast, concepts such as "identity", "culture", "nation", and "Capeverdean-ness" tend play a central role.
\end{abstract}

Keywords: Cape Verde - social class - race - ethnicity 